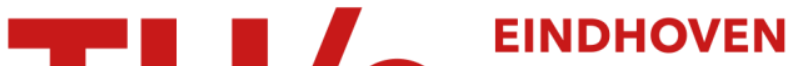 UNIVERSITY OF TECHNOLOGY
}

\section{Analysis of stresses in two-dimensional models of normal and neuropathic feet}

\section{Citation for published version (APA):}

Patil, K. M., Braak, L. H., \& Huson, A. (1996). Analysis of stresses in two-dimensional models of normal and neuropathic feet. Medical and Biological Engineering and Computing, 34(4), 280-284.

\section{Document status and date:}

Published: 01/01/1996

\section{Document Version:}

Publisher's PDF, also known as Version of Record (includes final page, issue and volume numbers)

\section{Please check the document version of this publication:}

- A submitted manuscript is the version of the article upon submission and before peer-review. There can be important differences between the submitted version and the official published version of record. People interested in the research are advised to contact the author for the final version of the publication, or visit the $\mathrm{DOI}$ to the publisher's website.

- The final author version and the galley proof are versions of the publication after peer review.

- The final published version features the final layout of the paper including the volume, issue and page numbers.

Link to publication

\section{General rights}

Copyright and moral rights for the publications made accessible in the public portal are retained by the authors and/or other copyright owners and it is a condition of accessing publications that users recognise and abide by the legal requirements associated with these rights.

- Users may download and print one copy of any publication from the public portal for the purpose of private study or research.

- You may not further distribute the material or use it for any profit-making activity or commercial gain

- You may freely distribute the URL identifying the publication in the public portal.

If the publication is distributed under the terms of Article $25 \mathrm{fa}$ of the Dutch Copyright Act, indicated by the "Taverne" license above, please follow below link for the End User Agreement:

www.tue.nl/taverne

Take down policy

If you believe that this document breaches copyright please contact us at:

openaccess@tue.nl

providing details and we will investigate your claim. 


\title{
Analysis of stresses in two-dimensional models of normal and neuropathic feet
}

\author{
$\begin{array}{lll}\text { K. M. Patil } & \text { L. H. Braak } & \text { A. Huson }\end{array}$ \\ ${ }^{1}$ Biomedical Engineering Division, Department of Applied Mechanics, Indian Institute of \\ Technology, Madras, India \\ 2 Department of Fundamentals of Mechanical Engineering; Eindhoven University of Technology, \\ Eindhoven, The Netherlands \\ ${ }^{3}$ Centre for Biomedical and Health Care Technology, PO Box 513, 5600 MB Eindhoven, \\ The Netherlands
}

\begin{abstract}
A two-dimensional model of the normal foot skeleton, which includes cartilages and ligaments, is used in this analysis of stresses during three quasi-static walking phases: heel-strike, mid-stance and push-off. It is found that in all the walking phases the maximum values of principal stresses occur in the dorsal anterior region of the talus, whereas the highest stress occurs in the push-off phase. The model is used for the simulation of muscle paralysis and its effect on the distribution of principal stresses. Subsequently, the model is used to analyse stresses in the deformed feet of three leprosy patients with complete paralysis of certain muscles. The results demonstrate that both the shape of the foot and the type of muscle paralysis contribute to the development of high stresses in different regions of the foot. These high stresses in regions with reduced mechanical strength could be one of the important factors in the process of tarsal disintegration in leprosy.
\end{abstract}

Keywords-Finite element, Neuropathic feet, Stress analysis, Two-dimensional foot model

Med. \& Biol. Eng. \& Comput., 1996, 34, 280-284

\section{Introduction}

THE INTERNAL stress developed in the foot skeleton cannot be measured directly in vivo or post mortem. However, using a modelling procedure such stresses can be predicted. We have previously developed two-dimensional single bone models of the foot to study the stress patterns in three quasi-static situations of the foot, representing heel-strike, mid-stance and push-off (PATIL et al., 1993a). We have also developed a twodimensional model of a normal foot (in mid-stance) that enabled simulation of articulations (joints) step-wise to analyse concurrent stress patterns (PATIL et al., 1993b). In those studies only one muscle was active in each of the three positions: the tibialis anterior (TA) during heel-strike and the triceps surae (TS) during mid-stance and push-off (PATIL et al., 1993a;b).

In this study, we report on the effects on the stress states of this model in mid-stance when more active muscles are included. The same model is used to calculate stress patterns in two other quasi-static situations, heel-strike and push-off, and in situations where one or more muscles are assumed to be paralysed due to accidents or diseases like leprosy or diabetes. In an attempt to explain tarsal disintegration, the combined effects of a deformed foot with changed geometries and muscle paralysis are investigated.

The stress calculations are carried out using GIFTS, a finiteelement software package*, which is suited for linear material behaviour and small displacements.

\footnotetext{
* CASA/GIFTS Inc., Tucson, Arizona

First received 10 August 1994 and in final form 2 October 1995.
}

(C) IFMBE: 1996

\section{Model}

\subsection{Normal foot}

Many muscles responsible for foot movement (but not most of them) have very long tendons. They are located in the lower leg and produce motion in the ankle joint (dorsal and plantar flexion), as well as in the tarsal joints (inversion and eversion) and in the metatarsophalangeal joints (flexion and extension of the toes). As they are attached to many of the foot bones, they also contribute to stresses in the bones.

The guide point for muscles going around medial pulley(point $\mathrm{P}_{1}$ ) represents the sustentaculum tali, which is the medial part of the calcaneus (Fig. 1). With its groove underneath, it acts as a pulley for the tibialis posterior (TP) and flexor hallucis longus (FHL). A less prominent but similar bony protuberance, with a similar location at the lateral side of the calcaneus serves the peroneous longus (PL). It is an effect at the lateral surface of the calcaneus, although the insertion of the PL is on the medially located first cuneiform. The PL crosses the foot at the plantar side.

All these muscles are guided by tendon sheaths attached to the described bony prominences. The extensor hallucis longus (EHL) and tibialis anterior (TA) are guided by a tendinous sling attached at $\mathbf{P}_{2}$, a point located somewhat more proximal to the pulley's site of $\mathrm{P}_{1}$. The various muscle forces (BASMAJIAN, 1978; INMAN et al., 1981) that are active in the normal articulated foot model and the ankle joint force are shown in Fig. 1. Not all the muscles are active in each of the three quasistatic walking positions: heel-strike (HS), mid-stance (MS) and push-off (PO). For this 2-D model, only force components with an effect in the sagittal plane have been considered. 


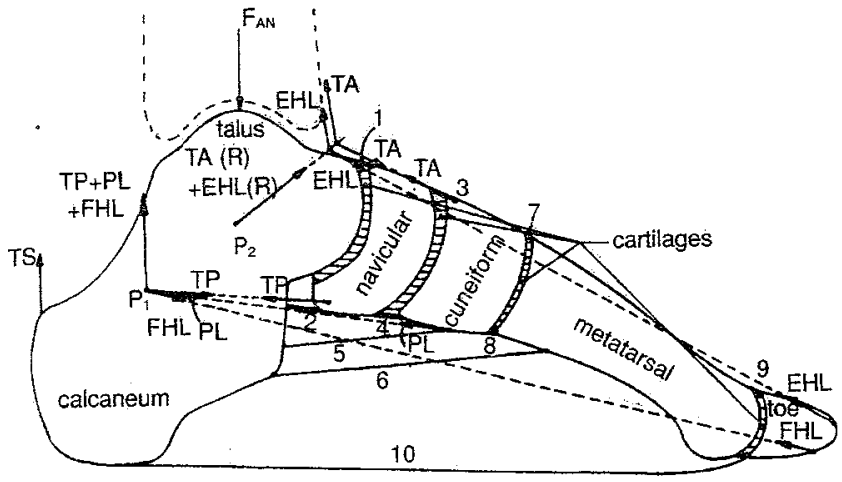

Fig. 1 Muscle forces and ankle joint force acting on the twodimensional model of the foot skeleton; $P_{1}=$ guide point for muscles going round medial pulley; $P_{2}=$ attachment point of slip guiding muscles $E H L$ and $T A ; F_{A N}=$ ankle joint force; $T S=$ tricep surae; $P L=$ peroneous longus; $F H L=$ flexor hallucis longus; $T P=$ tibialis posterior; $E H L=$ extensor hallucis longus; $T A=$ tibialis anterior; $1-10=$ ligaments

Table 1 presents the active muscles and the magnitudes of their (mean) forces. The magnitudes of the ankle joint forces are obtained from previous work by Röhrl et al. (RöHRL, 1984). The magnitudes of the muscle forces are obtained from previous work by Seireg and Arvikar and Calderale and Scelfo, and by using force equilibrium equations for the unknown muscle forces EHL in heel-strike and PL in the mid-stance and push-off position of the foot (SEIREG and ARVIKAR, 1975; CALDERALE and SCELFO, 1987).

In heel-strike, the foot is in dorsiflexion and the foot sole is inclined $30^{\circ}$ with respect to the horizontal, whereas in push-off the foot is in plantar flexion and the inclination is $45^{\circ}$ (BASMAJIAN, 1978; INMAN et al., 1981). The actual geometry of the foot is obtained from a medial-lateral X-ray of a normal foot. The directions and the attachment points of the tendons are based on anatomical considerations (WILLIAMs et al., 1989). Young's modulus and Poisson's ratio of the cartilages are taken as $10 \mathrm{MPa}$ and 0.4 , respectively, (SCHREPPERS et al., 1990; BROWN et al., 1980) and the corresponding values for bone are $7300 \mathrm{MPa}$ and 0.3 (NAKAMURA et al., 1981). The stiffness of each ligament is taken as $1500 \mathrm{~N} \mathrm{~mm}^{-1}$ (PATL et al., 1993b).

\subsection{Foot with paralysed muscles}

In this section foot modelling involves the use of an articulated foot model (see Section 2.1) in the analysis of stresses, simulating paralysis in muscles due to accidents, leprosy or diabetes. In heel-strike, if EHL is paralysed, it is

Table I Magnitudes of bone and mean muscle forces in the walking phases heel-strike, mid-stance and push-off

\begin{tabular}{lccc}
\hline & HS, N & MS, N & PO, N \\
\hline tibialis anterior (TA) & 500 & - & - \\
extensor hallucis longus (EHL) & 231 & - & - \\
peroneous longus (PL) & - & 350 & 134 \\
flexor hallucis longus (FHL) & - & 400 & 50 \\
tibialis posterior (TP) & - & - & 400 \\
triceps surae (TS) & - & 600 & 1100 \\
ankle joint force, $\mathrm{F}_{\mathrm{AN}}$ & 1350 & 2100 & 3000 \\
& $(2.25 W)$ & $(3.5 W)$ & $(5 W)$ \\
reaction force at $\mathrm{P}_{1}, \mathrm{R}_{1}$ & - & 1025 & 865 \\
reaction force at $\mathrm{P}_{2}, \mathrm{R}_{2}$ & 716 & - & - \\
\hline
\end{tabular}

$W=$ body weight of a normal person, here $600 \mathrm{~N}$; muscle and reaction forces represent mean values; in the calculations they have been varied between 0.9 and 1.1 times the mean value assumed that the force in the remaining active muscle (TA) increases to maintain quasi-static force equilibrium, given the ankle joint force from Table 1. Similarly, when FHL and/or TP are paralysed in mid-stance or push-off, it is assumed that the most powerful muscle (triceps surae, TS) will generate a greater force to maintain equilibrium. In each of these cases (see Table 2) the forces in paralysed muscles are taken as zero.

\subsection{Leprotic foot}

As leprosy patients have deformed feet in addition to a partial or complete paralysis of certain muscles, this analysis considers the shape of the foot (obtained from X-rays) and the muscle status (regarding conditions of paralysis) from clinical data. The foot model is applied to three leprosy patients, with feet in different stages of tarsal disintegration, for the analysis of stresses.

Fig. 2 shows the geometry of the right foot model, along with forces acting in the mid-stance phase of patient MLW. This patient has paralysed right foot dorsiflexors (TA and EHL) and FHL, and a portion of the navicular bone is emerging which appears to be chipped off at the upper part. An X-ray of the foot shows an early stage of tarsal disintegration. The loading of the model accounts for the paralysis of muscles.

The second patient KTD is in an intermediate stage of tarsal disintegration; he has completely paralysed right foot dorsiflexors (TA and EHL) and FHL, and extremely shortened metatarsals (his forefoot is virtually resting on the remains of

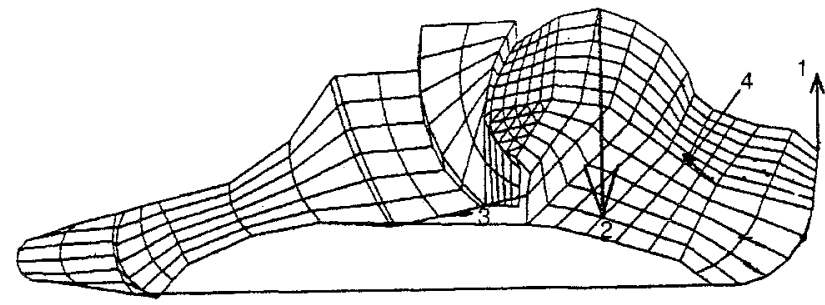

Fig. 2 Two-dimensional model and the finite-element mesh in the deformed and paralysed foot of the leprotic patient $M L W$ in mid-stance phase; forces in $1=T S, 2=F A N, \quad 3=P L$, $4=$ reaction force $R_{1}$ at the guide point $P_{1}$ due to $P L$

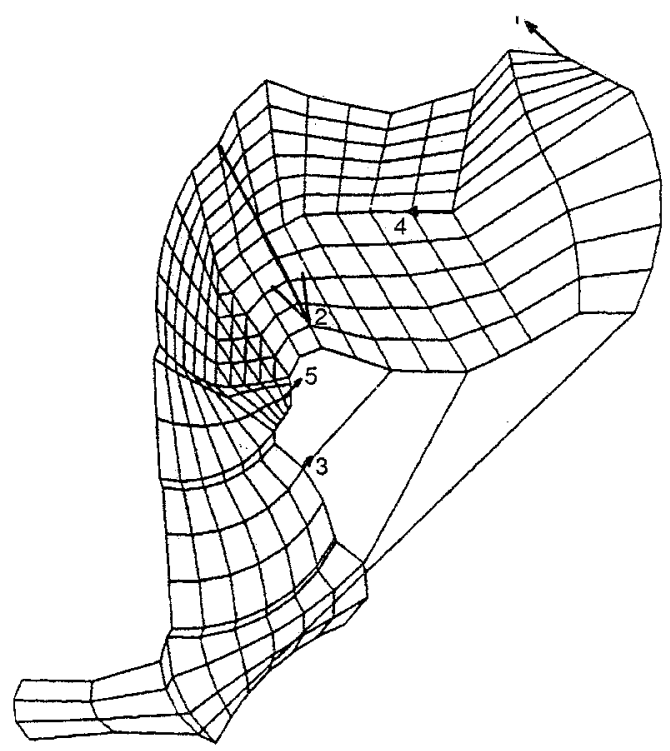

Fig. 3 Two-dimensional model and the finite-element mesh in the deformed and paralysed foot of the leprotic patient KTD in push-off phase; forces in $1=T S, 2=F A N, 3=P L$, $4=$ reaction force $R_{1}$ at the guide point $P_{1}$ due to $P L$ and $T P, 5=T P$ 
Table 2 Magnitudes of bone and mean muscle forces in the active muscle during the simulated walking phases heel-strike, mid-stance and push-off with paralysed muscles

\begin{tabular}{lcccccccc}
\hline & $\mathrm{HS}_{1}, \mathrm{~N}$ & $\mathrm{HS}_{2}, \mathrm{~N}$ & $\mathrm{MS}_{1}, \mathrm{~N}$ & $\mathrm{MS}_{2}, \mathrm{~N}$ & $\mathrm{PO}_{1}, \mathrm{~N}$ & $\mathrm{PO}_{2}, \mathrm{~N}$ & $\mathrm{PO}_{3}, \mathrm{~N}$ & $\mathrm{PO}_{4}, \mathrm{~N}$ \\
\hline $\mathrm{TA}$ & $\mathrm{FP}$ & 724 & - & - & - & - & - & - \\
$\mathrm{EHL}$ & 742 & $\mathrm{FP}$ & - & - & - & - & - & - \\
$\mathrm{TP}$ & - & - & - & - & 400 & $\mathrm{FP}$ & $\mathrm{FP}$ & $\mathrm{FP}$ \\
$\mathrm{PL}$ & - & - & $\mathrm{FP}$ & 350 & $\mathrm{FP}$ & 134 & $\mathrm{FP}$ & $\mathrm{FP}$ \\
$\mathrm{FHL}$ & - & - & 400 & $\mathrm{FP}$ & 50 & 50 & 50 & $\mathrm{FP}$ \\
$\mathrm{TS}$ & - & - & 874 & 920 & 1210 & 1440 & 1555 & 1596 \\
$R_{1}$ & - & - & 522 & 507 & 676 & 252 & 63 & - \\
$R_{2}$ & 696 & 724 & - & - & - & - & - & - \\
\hline
\end{tabular}

$\mathrm{HS}_{1}, \mathrm{HS}_{2}, \ldots, \mathrm{PO}_{4}=$ several simulations of walking phases with paralysed muscles. $\mathrm{FP}=$ fully paralysed, $\mathrm{TA}=$ tibialis anterior, $\mathrm{EHL}=$ extensor hallucis longus, $\mathrm{TP}=$ tibialis posterior, $\mathrm{PL}=$ peroneous longus, $\mathrm{FHL}=$ flexor hallucis longus, TS = triceps surae, $R_{1}=$ reaction force at pulley point $1, R_{2}=$ reaction force at pulley point 2 ; calculated forces are in italics; other forces (ankle joint forces, muscle forces and bone reaction forces) are assumed to have the values in Table 1 . indicates an inactive muscle or absent reaction force

the metatarsal base). This is shown in Fig. 3, which provides the geometry of the foot in push-off phase, along with the muscle and ankle forces acting on the model.

The third patient KLPS is in an advanced stage of tarsal disintegration, with his left foot with a collapsed arch and portions of the cuneiform and metatarsals protruding. In the mid-foot region the foot has the shape of a rocker foot. The dorsiflexors and FHL are completely paralysed.

Table 3 presents the magnitudes of (mean) load values acting on the foot model for the three patients; these values are determined in the same way as in Section 2.2. To obtain an insight into the sensitivity of the stresses for load variations, calculations are carried out with variations of $\pm 10 \%$ in the mean value of the magnitudes of the muscle forces presented in Tables 1-3.

\section{Results}

\subsection{Normal foot}

The finite-element calculations of a 2-D model of a normal foot, with active muscles, show that in each quasi-static walking phase the dorsal anterior regions of the talus bordering the cartilage between the talus and the navicular have the highest maximal principal stress. Fig. 4 presents the von Mises stress contours during the push-off phase and shows the most highly stressed region.

The mean values of maximum principal stresses in the three phases (heel-strike, mid-stance and push-off) are in the ratio $1: 1.5: 3.25$; in magnitude $26.7 \pm 0.4 \mathrm{~N} \mathrm{~mm}^{-2}$; $40.5 \pm 2.0 \mathrm{~N} \mathrm{~mm}^{-2}$ and $83.5 \pm 0.6 \mathrm{~N} \mathrm{~mm}^{-2}$. It is observed that in most parts of the model the principal stress in a point is compressive, although in the most highly stressed regions there is also a tensile component (especially in the anterior dorsal region of the talus).

\subsection{Foot with paralysed muscles}

The results presented here (except for TA paralysis where the most highly stressed region is the toe) indicate the changes in the maximum values of the principal stresses in the dorsal anterior region of the talus, compared with the corresponding normal mean values.

3.2.1 Heel-strike position: complete loss of the motor functions of the TA means that other extensors of the foot (EHL in our simplified model) need to deliver all the force needed for equilibrium. It is therefore not surprising that the upper toe region is now far more loaded than in a normal foot; the stresses in the toe region are 2.3 times higher than the corresponding normal value of $12.6 \mathrm{~N} \mathrm{~mm}^{-2}$.
Table 3 Magnitudes of bone and mean muscle forces used in the simulated walking phases of three leprosy patients (MLW, KTD and $K L P S)$

\begin{tabular}{lrrrrr}
\hline & \multicolumn{2}{c}{ mid-stance } & & push-off \\
& MLW, N & KTD, N & MLW, N & KTD, N & KLPS, N \\
\hline FHL & FP & FP & FP & FP & FP \\
PL & 350 & 350 & 66 & 133 & FP \\
TP & - & - & 400 & 400 & FP \\
TS & 795 & 170 & 1100 & 714 & 1596 \\
$R_{1}$ & 465 & 407 & 723 & 689 & \\
\hline
\end{tabular}

Ankle joint forces, muscle forces and bone reaction forces are assumed to be similar to those in Table 1; - indicates inactive muscle; due to muscle paralysis these patients have no heel-strike; mid-stance and push-off are similar in patient KLPS due to clinical muscle paralysis and the particular geometry of his rocker foot

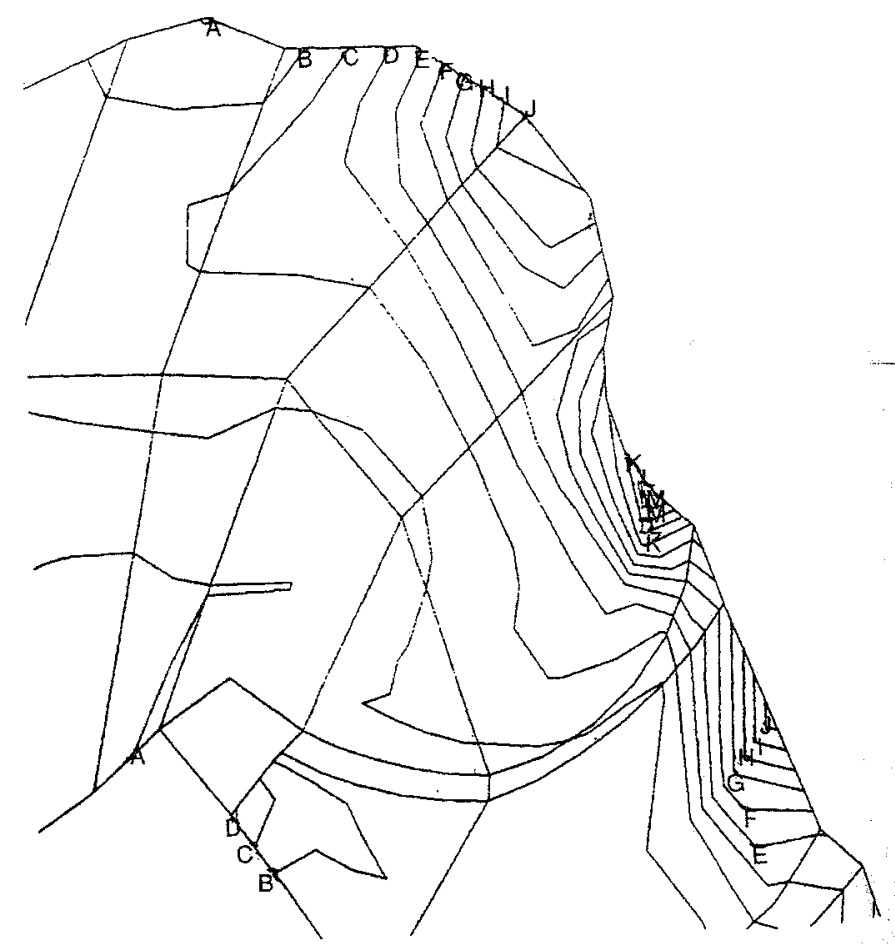

Fig. 4 Von Mises stress contours in the higher stressed region (dorsal anterior part of talus) of the two-dimensional model of the normal foot during push-off: $A=5 \cdot 0, B=10, C=15$, $D=20, E=25, F=30, G=35, H=40, \quad I=45, \quad J=50$, $K=55, L=60, M=65, N=70, O=75, P=80$ 
Complete paralysis of the EHL increases the stress by $6 \%$. As the lines of action of the EHL and TA are nearly the same, the stresses in the dorsal anterior region of the talus are not significantly influenced by paralysis of the EHL and the corresponding increase in the compensating TA force.

3.2.2 Mid-stance position: results show that a complete paralysis of PL increases the maximum principal stresses occurring at the dorsal anterior part of the talus by $3-9 \%$ of the normal value $\left(40.5 \mathrm{~N} \mathrm{~mm}^{-2}\right)$ for a $10 \%$ variation in mean muscle forces. Complete paralysis of the FHL produces in this model a $0.4-3.2 \%$ increase in stresses at the same region.

3.2.3 Push-off position: it is observed that the increases in the maximum principal stress at the dorsal anterior region of the talus, for paralysis of TP or PL, are in the order of $4.6-4.9 \%$ and $1.3-2.3 \%$, respectively, of its normal mean value $\left(83.5 \mathrm{~N} \mathrm{~mm}^{-2}\right)$. Even when both muscles are paralysed, the influence of the greater value of TS force (see Table 2) produces only a slightly higher stress $(6-6.5 \%)$ of the mean maximum principal stress. Simulation of paralysis of all three muscles (TP, PL and FHL) makes the force exerted by the TS somewhat larger, as shown in Table 2, but again it results in only a small increase of $7 \%$ in the mean maximum principal stress.

\subsection{Leprotic foot}

The results are presented of the stress analysis on three typical leprosy subjects, with muscle paralysis and foot geometry changes due to foot deformities, caused by different degrees of tarsal disintegration. Fig. 5 shows the von Mises stress contours in the mid-stance phase for leprosy subject MLW, in an early stage of tarsal disintegration. The maximum principal stress of $73 \pm 2.3 \mathrm{~N} \mathrm{~mm}^{-2}$ occurs in the lower (plantar) anterior part of the calcaneus adjacent to the compressed thin layer of cartilage. This stress is $150 \%$ higher than the corresponding mid-stance stress in a normal foot model. The adjacent cartilages also show a maximum principal stress of $30 \mathrm{~N} \mathrm{~mm}^{-2}$, which is found to be 13 times higher than the normal cartilage stress.

The analysis of stresses during the push-off phase for the same subject shows a maximum principal stress of $119 \pm 0.5 \mathrm{~N} \mathrm{~mm}^{-2}$ in the compressed thin portions of the cartilage (nearer to the anterior plantar part of the calcaneus), whereas in the adjacent calcaneal bone the stress decreases to a value of $35 \mathrm{~N} \mathrm{~mm}^{-2}$. The alternating increase and decrease of

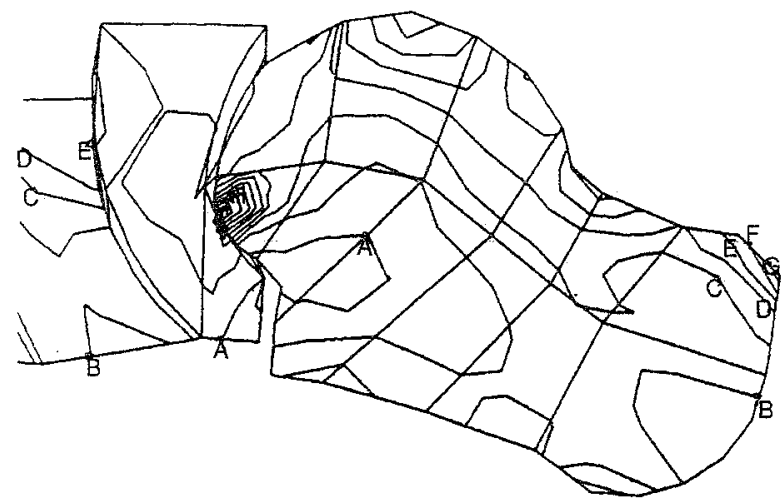

Fig. 5 Von Mises stress contours in the higher stressed region of deformed right foot model of the leprosy patient MLW, with paralysed dorsiflexors, during mid-stance; $A=5 \cdot 0, B=10$, $C=15, \quad D=20, E=25, \quad F=30, \quad G=35, \quad H=40, \quad I=45$, $J=50, K=55, L=60, M=65, N=70$

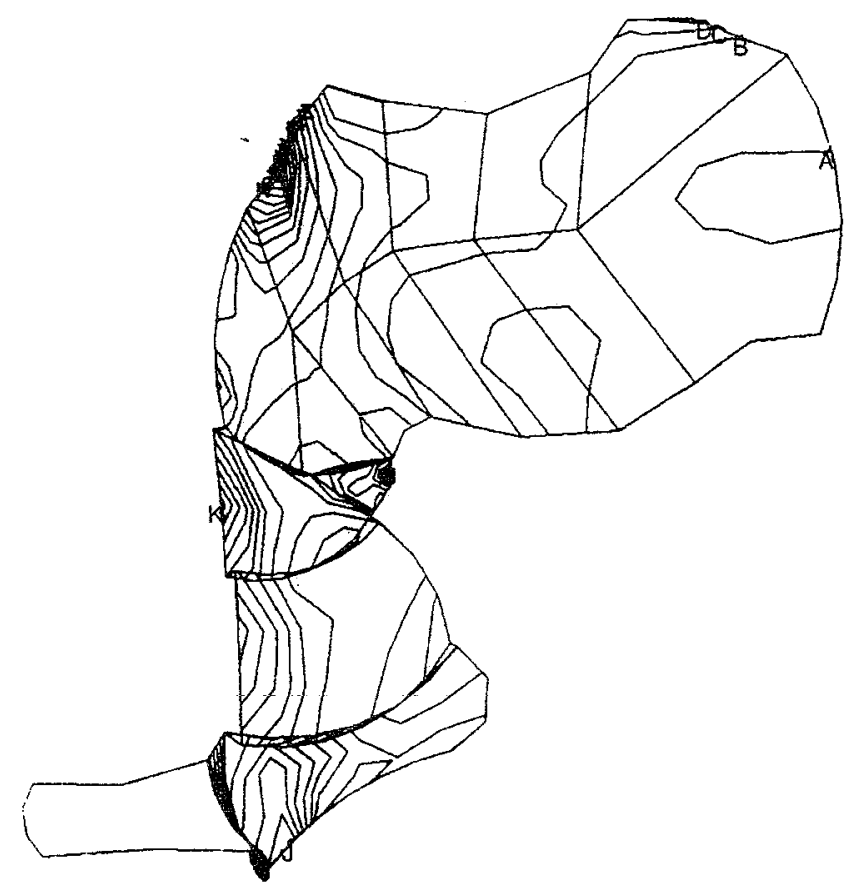

Fig. 6 Von Mises stress contours in the deformed right foot model of the leprosy patient $K T D$, with paralysed dorsiflexors, during push-off; $A=5 \cdot 0, B=10, C=15, D=20, E=25, F=30$, $G=35, \quad H=40, \quad I=45, \quad J=50, \quad K=55, \quad L=60, \quad M=65$, $N=70, O=75, P=80$

high compressive stresses in mid-stance and push-off phases in the above regions, and also in the upper (dorsal) part of the cartilage between navicular and cuneiform, might be responsible for the upwards projection of the navicular (as shown in Fig. 2) in this subject.

In the second leprosy subject KTD, with an intermediate stage of tarsal disintegration, the analysis of stresses during mid-stance simulation shows the maximum principal stress to be $55.5 \pm 0.5 \mathrm{~N} \mathrm{~mm}^{-2}$, occurring in the dorsal posterior region of the navicular. The stresses in the push-off phase indicate three regions of high stress (Fig. 6); lower anterior metatarsal head, plantar and proximal part of navicular and dorsal anterior part of the talus. The maximum principal stress in the metatarsal head is found to be $82 \pm 1 \mathrm{~N} \mathrm{~mm}^{-2}$, which is

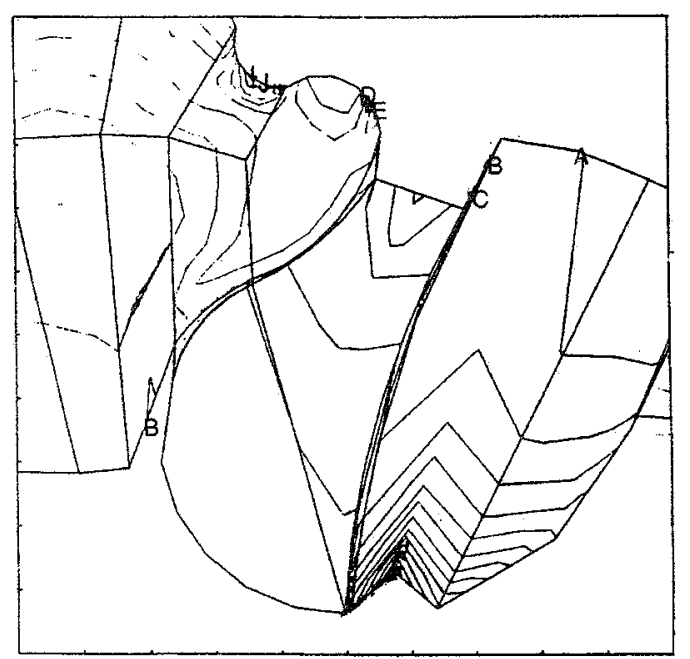

Fig. 7 Von Mises stress contours in the deformed left foot model of the leprosy patient KLPS, with paralysed dorsiflexors, during push-off; $A=5.0, B=10, C=15, D=20, E=25, F=30$ $G=35, H=40, \quad I=45, J=50, \quad K=55, L=60, \quad M=65$ $N=70$ 
four times the stress value in the corresponding region of a normal foot model. The maximum principal stresses in the plantar proximal part of the navicular and dorsal anterior part of the talus are in the order of $83.5 \pm 0.5 \mathrm{~N} \mathrm{~mm}^{-2}$. The high stresses in the above regions could be responsible for the disintegration of the tarsal bones and may result in the deformed shape of the foot, as observed in the X-ray:

In the third leprosy patient KLPS, in an advanced stage of tarsal disintegration, the analysis of stresses during push-off simulation shows the maximum principal stress to be $73 \pm 1.5 \mathrm{~N} \mathrm{~mm}^{-2}$, occurring at the downwards (plantarward) protruding posterior part of the metatarsal base (Fig. 7). It is interesting to note that this patient has an ulcer at the same spot.

\section{Discussion and conclusions}

It is found that in the articulated 2-D normal foot model the maximum principal stress occurs at the anterior dorsal part of the talus, bordering the cartilage between the talus and the navicular, in all three quasi-static walking phases. The maximum principal stresses for the articulated normal foot model during heel-strike, mid-stance and push-off are in the ratio $1: 1 \cdot 5: 3 \cdot 25$. According to orthopaedic surgeons, arthrosis sometimes develops in the above-mentioned highly stressed regions of the talus. Simulation of complete paralysis of the tibialis anterior in heel-strike increases the maximum principal stress occurring at the toes by $2 \cdot 3$ times the corresponding stress in the normal articulated foot model. This result may indicate the impossibility of long toe extensors, like EHL, replacing the TA, which is why a person with TA paralysis walks with a flapping foot.

Simulation of paralysis of another single muscle in the midstance or push-off phase results in a small increase in the maximum principal stress in the talar region. The paralysis of muscles with a nearer insertion site with respect to the ankle joint (such as TA or TP) increases the stresses in the talar region more than the paralysis of muscles such as EHL or FHL. The stress analysis for leprosy subjects, as discussed above, shows the interesting combined effects of foot shape and muscle paralysis on the development of high stresses in certain regions of the foot. If the mechanical strength of the bone is reduced due to osteoporosis or cystic degeneration in these regions, these high stresses may possibly contribute to tarsal disintegration. Clinical findings also confirm that the navicular, talus and metatarsals in the above-stated regions of some leprosy patients undergo disintegration (KULKARNI et al., 1985).

In this study a complete linear analysis was carried out using linear elastic material properties. Using a soft tissue pad under the foot skeleton introduces viscoelastic effects for which the finite element code used (GIFTS) is not very well suited. In the development of more appropriate models of the foot, an extension to three-dimensional models is perhaps more adequate than the introduction of soft tissue. Nevertheless, it is expected that in quasi-static analyses the effect of soft tissue is only noticeable on the plantar pressures between foot and ground.

Acknowledgments - The authors would like to thank The Netherlands Foundation for Advanced Tropical Research (WOTRO), The Hague, for the grant of a fellowship to $K$ M. Patil to conduct the above research.

\section{References}

BASMAJIAN, J. V. (1978): 'Muscles alive-their function revealed by electro-myography' (Williams \& Wilkins Co., Baltimore) pp. $247-$ 277

Brown, T. D., WAY, M. E., FU, F. H., and FERGuSON, A. B. (1980): 'Some growth related changes in the distribution of stress in the proximal juvenile femur'. Proc. Int. Conf. on Finite Elements in Biomechanics, Tucson, University of Arizona, USA, vol. 1, pp 129-145

CALDERALE, P. M., and SCELFO, G. (1987): 'A mathematical model of the locomotor apparatus', Eng. Med., 16, pp. 147-161

KULKARNI, V. N., MEHTA, J. M., SANE, S. B., and ShaRANGAPANI, R. C. (1985): 'Study of tarsal disintegration in leprosy'. Proc. Int. Conf. on Biomechanics and Clinical Kinesiology of Hand and Foot, Indian Institute of Technology, Madras, pp. 121-124

INMAN, V. T., RALSTON, H. J., and TODD, F. (1981): 'Human walking' (Williams and Wilkins, Baltimore)

WILLIAMS, P. L., WARWICK, R., DYSON, M., and BANNISTER, L. H. (Eds.): (1989) 'Gray's anatomy' (Churchill Livingstone, New York) 37th edn.

NAKAMURA, S., CROWNSHIEld, R. D. and COOPER, R. R. (1981): 'An analysis of soft tissue loading in the foot-a preliminary report', Bull Prosthetic Res., 18, pp. 27-34

PATIL, K. M., BRAAK, L. H., and HusON, A. (1993a): 'Stresses in a simplified two dimensional model of a normal foot-a preliminary analysis', Mech. Res. Commun., 20, (1), pp. 1-7

Patil, K. M., BraAK, L. H., and Huson, A. (1993b): 'A two dimensional model of a normal foot with cartilages and ligaments for stress analysis', Innov. Tech. Biol. Med., 14, (2), pp. 152-162

RÖHRL, H., SCHOLTEN, R., SIGOLOTTO, C., and SOLLBACK, W. (1984): 'Joint forces in the human pelvis-leg skeleton during walking', $J$. Biomech., 17, (6), pp. 409-424

SCHREPPERS, G. J. M. A., SAUREN, A. A. H. J., and Huson, A. (1990): 'A numerical model of the load transmission in the tibio-femoral contact area', Proc. Inst. Mech. Eng., 204, pp. 53-59

SEIREG, A., and ARVIKAR, R. J. (1975): 'The prediction of muscular load sharing and joint forces in the lower extremities during walking', J. Biomech., 8, pp. 89-102

\section{Authors' biographies}

K. Mothiram Patil received his DSc in Biomedical Engineering from Washington University, St. Louis, USA, in 1971. Currently, he is Professor of Biomedical Engineering in the Department of Applied Mechanics, IIT Madras. His research interests are biomechanics and rehabilitation engineering.

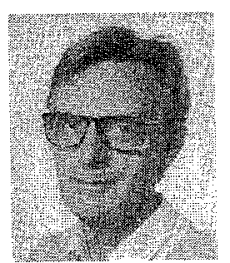

Leo H. Braak $\mathrm{PhD}$ is a lecturer in Continuum Mechanics at the Eindhoven University of Technology and at the Department of Movement Sciences at the State University of Limburg, The Netherlands. His research interests are education, biomechanics and consultancy.

Anthony Huson, $\mathrm{MD}, \mathrm{PhD}$, is Professor of Functional Anatomy in the Department of Fundamentals of Mechanical Engineering, and advisor of the Center for Biomedical and Health-care Technology, Eindhoven University of Technology. His research interests are the locomotion system with emphasis on the lower limb. 